Marquette University

e-Publications@Marquette

College of Nursing Faculty Research and

Publications

Nursing, College of

$1-1-2004$

\title{
The Future of Professional Education in Natural Family Planning
}

Richard Fehring

Marquette University, richard.fehring@marquette.edu

Accepted version. Journal of Obstetric, Gynecologic, \& Neonatal Nursing, Vol. 33, No. 1 (January 2004): 34-43. DOI. (C) 2004 Blackwell Publishing. Used with permission. 


\section{The Future of Professional Education in Natural Family Planning}

Author: Richard J. Fehring

\section{Abstract:}

Nurses and other health care professionals often have little knowledge of methods of natural family planning (NFP) and do not readily prescribe natural methods for their patients. One reason for this is that little or no information on NFP is provided in nursing or medical schools. The holistic, informational, and integrative nature of NFP fits well with professional nursing practice. A university online distance education NFP teacher training program, which offers academic credit and includes theory, practice, and the latest developments in fertility monitoring, has been developed for health care professionals. Professional NFP services in the United States need to meet worldwide standards and include documenting and assessing pregnancy outcomes, tailoring NFP services to the client or couple, and simplifying them for ease of use in a standard health care practice.

Modern methods of natural family planning (NFP) (such as the ovulation method and the sympto-thermal method) have been taught in the United States for more than 30 years.

Effectiveness studies of modern methods of NFP have confirmed that when used correctly they are effective in helping motivated couples to space pregnancy (correct use effectiveness rates vary from $97 \%$ to $99 \%$, Trussell, 1998); however, very few women in the United States (less than $3 \%$ of women between the ages of 15 and 44 ) use natural methods as a means of family planning (Fehring \& Schlidt, 2001; Hatcher et al., 1998; Howard \& Stanford, 1999; Piccinino \& Mosher, 1998). Women are reluctant to use NFP methods for family planning because of incompatible lifestyles, personal choice, lack of knowledge, lack of access, perceptions of ineffectiveness, and difficulty of use (Fehring, 1995). Another reason is that persons in influential positions (for example, physicians and nurses) have little knowledge of NFP and do not promote or trust the use of NFP as a means of child spacing (Fehring, Hanson, \& Stanford, 2001). This article provides a brief overview of NFP methods and health professionals' knowledge and use of NFP, defines professional NFP education, describes a for-credit distance education NFP teacher training program in a college of nursing, and offers a futuristic view of NFP education and service through the lens of recent NFP research.

\section{Methods of NFP}

Four general methods of NFP are used and taught in the United States. The calendar

1 Fehring 
rhythm and basal body temperature (BBT) methods are considered to be old methods, whereas the two so-called modern methods are referred to as the ovulation method (OM or cervical mucus only) and the sympto-thermal method (STM). The modern methods also are sometimes referred to as single and multiple indicator methods.

The calendar rhythm methods were developed in the 1920s and early 1930s and entail using a simple mathematical formula that requires knowledge of the longest and shortest menstrual cycle over the past 6 to 12 months. The perceived ineffectiveness of the calendar methods is largely based on myth and not on systematic research. Modern variations of the calendar methods have recently been developed that stipulate a fixed number of days of fertility in the menstrual cycle (e.g., days 8-19) and the use of a simple bead-counting system to help women track their cycles. A recent study of 478 women users of the standard days method of NFP from three countries (Bolivia, Peru, and the Philippines) indicated that the fixed day method had a cumulative probability of pregnancy of $4.75 \%$ with correct use and an $11.96 \%$ probability of pregnancy with typical use (Arevalo, Jennings, \& Sinai, 2002).

Since the early 20th century, it has been known that a woman's body temperature elevates after ovulation. That knowledge of this natural marker of fertility has been used since the 1930s as a method of NFP alone or in combination with calendar formulas. In the first prospective effectiveness study of BBT, reported in 1968, 502 couples had a typical use effectiveness of 6.6 pregnancies per 100 woman-years when intercourse was confined to the post-BBT shift period (after the postovulatory rise in body temperature) and 19.3 pregnancies when intercourse occurred in both the pre- and postovulatory phases of the cycle (Marshall, 1968). Correct use of BBT only as a postovulatory method will result in a method effectiveness of close to $99 \%$ (Hatcher et al., 1998). Researchers have studied the use of the male partner's basal body temperature concomitantly with the woman's as a means to determine prospectively the postovulatory time of the cycle (Dunlop, Allen, \& Frank, 2001; Frank \& White, 1996).

Both the single indicator, mucus-only methods, and the multiple indicator, symptothermal methods, were developed in the last half of the 20th century. Single indicator methods use the cyclical estrogenic changes of cervical mucus to determine the beginning, peak, and end of the fertile phase of the menstrual cycle. A five-country World Health Organization (WHO) study (1981) of 725 ovulation method users yielded a method-related pregnancy rate of $2.2 \%$ and a typical use pregnancy rate of $22.3 \%$, of which $15.4 \%$ was due to conscious departure from the rules. There are a number of variants of the single indicator cervical mucus method, including a standardized form known as the Creighton Model (CrM) system and a simplified

\section{Fehring}


version, the Modified Mucus method. Researchers are investigating the effectiveness of a simple 2-day algorithm for the mucus-only system (2 consecutive dry days without mucus indicates an infertile state) in avoiding pregnancy (Jennings \& Sinai, 2001; Sinai, Jennings, \& Arevalo, 1999).

The combination of several natural indicators of fertility, including cervical mucus, BBT shift, calendar formulas, and cervical changes, are used in the various forms of the symptothermal methods (STMs). There are only a few comparative studies on NFP effectiveness. Some consider the STM to be more effective when used to avoid pregnancy than the singleindicator mucus method (Kambic, 2000). A recent European study that compared a doublecheck STM with a single-check STM found a $2.6 \%$ unintended pregnancy rate with the doublecheck and an 8.5\% unintended pregnancy rate with the single-check method (Freundl, 1999). The double-check method involves use of a calendar day formula and the observation of cervical mucus to determine the beginning of the fertile period and two biological markers to determine the end of the fertile phase (i.e., the peak in cervical mucus and temperature changes). The single-check method uses one biological indicator (cervical mucus) to determine the beginning of the fertile period and one indicator (temperature) to determine the end of the fertile period.

The 21st century has brought new technology for use in natural methods of family planning. Women in Europe now have available the Persona (Unipath, Bedford, UK), a handheld fertility device, to track the fertile and infertile phases of the menstrual cycle by monitoring urinary metabolites of estrogen and luteinizing hormone. The method pregnancy rate of a prototype of the Persona among 710 volunteer European women was $12.1 \%$ but decreased to $6.2 \%$ after a change in the algorithm built into the monitor (Bonnar, Flynn, \& Freundl, 1999). Persona is not available in the United States, although a similar handheld device (the Clearplan Easy Fertility Monitor, Unipath Diagnostics Inc., Waltham, MA) is available and measures metabolites of estrogen and luteinizing hormone. This device is used to achieve pregnancy. Researchers at Marquette University College of Nursing are currently investigating the effectiveness of the use of the Clearplan monitor as an aid to learning and using NFP to avoid pregnancy with other natural indicators (i.e., cervical mucus and BBT).

\section{Knowledge and Use of NFP Among Health Care Professionals}

A number of studies have documented the knowledge and use of NFP by health care professionals. Snowden, Kennedy, and Leon (1988) interviewed 375 physicians from four

\section{Fehring}


developing countries (Mauritius, Peru, the Philippines, and Sri Lanka) about their knowledge of what they called periodic abstinence and found that most lacked detailed knowledge of NFP methods and did not prescribe them in practice. Doring, Baur, and Frank-Herrmann (1990) conducted telephone interviews of 229 general practitioners and 237 gynecologists from Germany and discovered that only $6 \%$ of them prescribed NFP as the main method of family planning and only $10 \%$ recommended the NFP method. One hundred twenty-one Italian family practice physicians responded to a questionnaire on the use of contraception and NFP in a study by Girotto et al. (1997). Findings indicated that more than $50 \%$ of the physicians knew little about NFP methods, $91.8 \%$ never or rarely recommended them, and only $8 \%$ would prescribe NFP for their patients. Stanford, Thurman, and Lemaire (1999) obtained a mailed survey response rate of 547 of $840(65 \%)$ from randomly selected State of Missouri family practice, general practice, and internal medicine physicians and obstetrician-gynecologists and found that only $10 \%$ of them offered NFP as a viable option to patients.

Two studies investigated the knowledge and use of NFP among nurses. Fehring (1995) surveyed 118 perinatal nurses and 48 physicians about their knowledge and use of NFP. Fiftythree percent of the nurses and $44 \%$ of the physicians would not advise the use of NFP to avoid pregnancy. The average amount of time that nurses and physicians were provided information about NFP in nursing or medical school was less than 1 hour. Finally, a study to determine the knowledge and use of NFP among a nationally randomized sample of 514 certified nurse midwives found that the CNMs ranked NFP as the 9th most effective family planning method used in their practice, with an average perceived method effectiveness of $88 \%$ and use effectiveness of $70 \%$ (Fehring et al., 2001). The majority of the respondents (92\%) felt minimally prepared by their educational program to provide NFP, yet $55 \%$ indicated that they could or would provide it on request.

After reviewing health care providers' lack of preparation in NFP, Fehring (1995) recommended that professional natural family planning teacher training programs be offered in nursing and medical schools. Natural family planning teacher training is a good fit for professional nursing education in that NFP is holistic, behavioral, and educational in nature. Furthermore, researchers have demonstrated that when NFP is presented in a positive light to women patients by health care providers, as many as $43 \%$ would be interested in using NFP to avoid or achieve pregnancy (Stanford, Lemaire, \& Fox, 1994; Stanford, Lemaire, \& Thurman, 1998).

\section{What Is Professional Education in NFP?}

4 Fehring 
Contemporary education in NFP is complex and involves science, philosophy, and art. The basic components of NFP science are the physiological understanding of natural biological markers of fertility, the accuracy of those markers in relation to the day of ovulation, and the effectiveness of biological markers in helping couples to achieve and avoid pregnancy. An understanding of the statistical parameters of the menstrual cycle and the probability of pregnancy are also important to the use and understanding of NFP. The philosophy of NFP includes understanding the meaning of the human person, human relationships, human sexuality, and the transmission of life. The art of NFP is complex and involves developing effective and efficient systems of NFP service. Systems of NFP include charting and documentation systems, educational materials, and teaching pedagogy. Other topics required to understand and provide professional NFP services are sexual ethics, family dynamics, psychological aspects of family planning, teaching methods, adult education principles, and program management.

\section{Core Components of Professional NFP Services}

The three core components of professional NFP services are NFP decision making, professional documentation, and integration of NFP services into women's health care (see Figure 1). NFP decision making includes assessing the client, couple, or NFP population of interest; determining the best NFP method for that individual or group; and assessing the effectiveness of that method. NFP decision making also includes determining the appropriate teaching methods and educational materials and assessing behavioral, ethical, and spiritual concerns.

Professional documentation in delivering NFP services, at a minimum, includes registration and initial assessment, follow-up, pregnancy evaluation, and discontinuation of NFP (Gray \& Kambic, 1984). NFP follow-up involves assessing and documenting the accuracy and completeness of charting, the client's understanding of instructions for achieving or avoiding pregnancy, the management of special circumstances (such as a mother who is breastfeeding and a woman who is coming off of hormonal contraception), the client's intention of use, and determination of satisfaction and autonomy. Pregnancy evaluation and documentation involves assessing the NFP chart, determining the day of conception, assessing whether the pregnancy was intended or not, and determining whether the pregnancy was a result of method failure or use failure and why. Data management and quality control measures are also important components of a professional NFP teacher-training program.

Health care professionals and other providers of NFP services also integrate the use of

\section{Fehring}


NFP into women's health concerns. Just learning about male and female human reproduction and gaining an awareness of the fertile and infertile times of a cycle is a health benefit. Variations from normal cyclical patterns can indicate potential health problems, such as unusual bleeding, cervical or vaginal infections, polycystic ovaries, and infertility. NFP providers aid breastfeeding women through times of uncertain fertility and support them in proper breastfeeding practices. Understanding menstrual cycle patterns in special circumstances such as the early phases after discontinuing hormonal contraception and during the perimenopause are concerns and a part of NFP practice. Professional nurse NFP teachers conduct functional pattern assessments to identify lifestyle patterns that might affect the menstrual cycle and fertility.

\section{NFP Educational Standards}

A professional NFP education program should meet established standards. Currently there are two organizations that provide standards for NFP teacher training programs, the American Academy of Fertility Care Professionals (AAFCP) and the Diocesan Development Program (DDP) for Natural Family Planning of the United States Catholic Conference of Bishops (USCCB) (DDP, 2000). The standards for the AAFCP are specific for the CrM system of NFP (Barron \& Daly, 2001). The USCCB standards are more generic and include faith-based criteria. In general, the standards from both organizations cover the need for a written and approved curriculum, goals and objectives, minimum content, qualified faculty, appropriate facilities and support systems (e.g., library facilities), an ongoing evaluation of the training program (including its content, faculty, and students), and adherence to a code of ethics. The code of ethics for the AAFCP is the most controversial standard, requiring that a participant not use, prescribe, or refer clients for contraception. The unmarried student also would be required to be sexually celibate and a philosophical supporter of NFP.

In the United States, there are a number of approaches to obtaining NFP teacher training. These include 1- to 4- day workshops, extensive continuing education training programs that include a supervised practice, and a university-based program that can be taken for academic credit. The USCCB lists 18 local, regional, and national programs that offer NFP teacher training and meet USCCB standards. These programs are not specifically intended for health care professionals and often include nonprofessional participants. The AAFCP has nine educational programs that have met academy accreditation standards. The largest of these is the Pope Paul VI Institute for the Study of Human Reproduction educational program that is cosponsored by the Creighton University School of Medicine.

\section{Fehring}


The Couple to Couple League International (CCL), a private, family-oriented support organization, provides a workshop that is specifically for health care professionals but not a teacher-training program. The workshop introduces participants to the sympto-thermal approach to NFP. Married health care professionals can take the CCL teacher training program in person or through distance education. Only married couples are trained as CCL teachers because the developers of the CCL program believed that the "couples teaching couples" method was the best means of providing information about NFP and related issues such as breastfeeding. The Billings Ovulation Method Association provides NFP teacher-training programs for those interested in teaching the Billings Ovulation Method. Other larger teacher training programs include the Family of the Americas Foundation (for the ovulation method) and Northwest Family Services (for the STM). See Table 1 for a listing of NFP teacher-training programs and Web site addresses.

One of the most extensive NFP teacher-training programs is offered by the Pope Paul VI Institute for the Study of Human Reproduction in affiliation with the Creighton University School of Medicine Division of Continuing Medical Education. This program lasts for 13 months and includes two intensive, 7-day, in-person educational phases and two supervised practica with a required onsite visit. Prescribing health professionals, including physicians, nurse practitioners, pharmacists, and nurse midwives, can also integrate a medical consultant program into this coursework. The Creighton University program covers primarily the intricacies of teaching the CrM system of NFP. The CrM is a standardized form of the ovulation method of NFP (Barron \& Daly, 2001). The medical consultant course includes the integration of NFP with women's health problems, which is called NaProTechnology (Pope Paul VI Institute for the Study of Human Reproduction, Omaha, NE).

\section{The Future of Professional Education in NFP}

Access to the Internet and Internet-based education is growing exponentially in the United States and the world. According to the U.S. Department of Commerce, as of 2002, more than $50 \%$ of U.S. households had access to the Internet. Each month, approximately 2,000 more people connect to the Internet. Phoenix University serves more than 100,000 students and offers more than 100 (graduate and undergraduate) degree programs through online courses. Penn State University started an online course offering in 1998 with 48 students, and today more than 1,600 students are enrolled in the university's online courses (Hons, 2002). Experts have estimated that approximately 6,000 accredited courses are offered online at more than

\section{Fehring}


$84 \%$ of U.S. 4-year institutions of higher education (Cuellar, 2002). More than 2 million students were enrolled in online courses in 2002 (Cuellar, 2002).

In the 2001-2002 academic year, Marquette University College of Nursing introduced the first professional, online, for-credit NFP teacher-training program based on the standards of the USCCB. Providing an NFP teacher-training program fits well within the Catholic Jesuit mission of the university. The Marquette University NFP teacher training program prepares the participant to provide professional NFP services and to qualify for certification through the Diocesan Development Program for NFP (a program of the USCCB). This educational offering is designed for health care professionals and involves a two-course sequence that includes a three-credit NFP theory course and a three-credit NFP supervised practicum. Both courses can be taken for undergraduate or graduate credit. The program was developed to meet the needs of nurses who wished to provide NFP services but who were unable to attend programs.

The three-credit NFP theory course is taught in nine modules that cover NFP history, anatomy and physiology, scientific foundations, fertility indicators, sexual ethics, family dynamics, adult teaching principles, program management, and other topics (see Table 2). The course is offered in the Blackboard online platform (Blackboard, Inc., Washington, DC) and includes chat rooms, slide media for lectures, profiles of each student and faculty, and online testing. Guest faculty, including NFP medical consultants (both family medicine and obstetrics) and clergy consultants, are present through synchronous and asynchronous discussion rooms. Students have numerous written requirements that include creating NFP brochures; writing papers on scientific developments; charting fertility indicators; summarizing church documents; and developing a parish-, college-, or hospital-based NFP service program, with a plan for marketing NFP services. Online participation in weekly discussions is required and is integral to the course.

The three-credit NFP practice course uses a case-study approach to the application of NFP theory and teaching skills. Students are assigned a personal preceptor and are required to teach a minimum of 10 new clients and present online case studies. (See Table 3 for an example case study used in the course.) In addition to learning to provide professional NFP services through group teaching sessions and individual follow-up sessions, the students become familiar with documentation, evaluation, and data management. The emphasis of the online practice course is on case presentations and problem management. The case examples presented are about special circumstances (such as women who are weaning their babies from breastfeeding and are not menstruating), and students, guest faculty, and seasoned NFP

\section{Fehring}


teachers provide feedback. Students and faculty also post interesting and complex cases online for feedback throughout the course.

All of the materials for the course are in digital format and are provided to the student in the online course media room, where files can be downloaded, viewed, and copied. Larger files are provided to the students in the form of a CD. The students are provided with a digital copy of all the necessary material to teach couples NFP, such as an NFP user manual, documentation forms, example and blank charts, and slides for group teaching sessions. All of the provided materials are in digital format and can easily be modified to fit the individual needs of the student and the various populations served.

Although the Marquette University College of Nursing NFP Teacher Training program is the only for-credit university-based program in the United States, there are other universitybased programs. The European General Assembly (EGA) of the European Institute of Family Life Education is currently assessing the need for a European certification of NFP teacher training programs. Their preliminary work with European parliamentarians has established that they need to address two important issues: One is to establish the minimum curriculum content for NFP teacher training programs and the other is to integrate these courses into the European universities. There currently are NFP courses in German, Spanish, Italian, and English universities. Members of the EGA have iterated that university-based programs would bring credibility to NFP. Furthermore, the discussion in European programs includes the incorporation of NFP teacher training into university-based nursing programs.

\section{Future Directions From Research}

Research on the topic of NFP and related areas in the past 5 years can give direction and reveal needs for professional education in NFP. Studies by Wilcox, Weinberg, and Baird, and Weinberg (1995) have helped to define and narrow the window of fertility in a woman's menstrual cycle to 6 days. This includes the day of ovulation and the 5 days before (based on evidence that sperm live from 3 to 5 days). Others have confirmed that the most fertile days of the menstrual cycle are the 2 days before ovulation (Dunson, Baird, Wilcox, \& Weinberg, 1999). This research will help NFP educational programs to focus on using natural fertility indicators to clearly define the beginning, peak, and end of the window of fertility and to help couples and clients to accurately pinpoint the days to achieve and to avoid pregnancy.

A number of effectiveness studies of NFP systems in the past few years have been published. They have confirmed that when you have motivated couples, competent NFP teachers, and well-developed NFP service programs, NFP methods can be very effective in

9 Fehring 
helping couples to both achieve and avoid pregnancy (Hilgers \& Stanford, 1998; Howard \& Stanford, 1999). However, very few studies on NFP effectiveness have been clinical trials with comparison groups (Lamprecht \& Trussell, 1997). Adherence to NFP method instruction and spousal support are key factors in high effectiveness rates (Tommaselli, Guida, \& Palomba, 2000). There is also the realization that the older calendar methods of NFP might be more effective than was previously thought (Kambic, 2000). Comparative studies of the effectiveness of the different methods of NFP need to be conducted. Educational programs have the effectiveness rates for both achieving and avoiding pregnancy and can provide effectiveness standards to students to use in evaluating their own NFP services.

Both high and low technology in fertility monitoring are helping to change professional education in NFP. The development of electronic fertility monitors that have the ability to measure urinary metabolites of estrogen, luteinizing hormone, and progesterone is helping to narrow the (self-monitored) window of fertility and provide for the direct measurement of female hormones (Behre, Kuhlage, \& Gassner, 2000; Bonner et al., 1999). Some of these devices are easy to use and do not have the variability that is found with temperature and cervical mucus monitoring. New algorithms for calendar rhythm, such as the fixed day method (i.e., days 8-19 or days 9-19 of the menstrual cycle are the days of fertility) and the 2-day method, and concomitant use of simple monitoring devices such as beads are helping to simplify both the use and the teaching of NFP (Burkhart, de Mazariegos, Salazar, \& Lamprecht, 2000; Jennings \& Sinai, 2001; Sinai et al., 1999). As NFP methods become simpler to teach, they can more readily be incorporated into professional practice.

Although only a few psychological studies of NFP have been conducted, findings from them can affect professional NFP education. Study results have shown that when women are provided with information about NFP in a positive light, as many as $40 \%$ have an interest in its use (Stanford et al., 1998). Studies of German NFP users found that they use NFP because it is safe, provides women with the power of information, and stimulates sexual desire (den Tonkelaar \& Oddens, 2001; Oddens, 1999). Because many women are fearful of pregnancy and some couples have difficulty with abstinence, NFP educational and service programs could be recommended for counseling couples in those areas. Little research exists on how methods of family planning, particularly NFP, affect marital and nonmarital relationships.

One area of need in professional NFP education is research on pedagogy and the integration of technology. Research on the best way of providing distance education in NFP is a need for both the professional NFP teacher and for the couple user. In some areas of the United

\section{Fehring}


States, there might be only one professional NFP teacher for an entire diocese, city, or even state. Distance education programs to train professional NFP teachers and distance couple training programs are needed. University-based schools of nursing would be the best places to develop and house such educational programs.

\section{Implications for Nursing}

Current NFP delivery systems are often NFP teacher and user intensive. Such NFP delivery systems usually entail introductory sessions that last an hour or more and individual follow-up sessions at monthly intervals for as long as 6 months (and sometimes longer). In today's fast-paced information age society, however, couples are often no longer willing or able to attend extensive educational sessions to learn how to use NFP. A professional NFP teacher may be the lone person trying to deliver services to a large area. Telemedicine and telehealth are options that can be used in such situations. Nurse researchers at Marquette University are currently developing a telehealth system of NFP services, which couples will be able to access on the Internet to learn NFP, obtain and download charts and users' manuals, and receive online feedback from health care professionals.

Another need is for simplified teaching and delivery of NFP services. Patient encounters in health care practice need to take place within a 20-minute time frame to be cost-effective. Current NFP services are education-based and counseling-intensive and do not fit readily into systems of short, episodic care. Arevalo (1997) suggested that more user-friendly methods of NFP could be developed by creating simplified versions of existing methods, streamlining teaching approaches, and developing new approaches and methods. Researchers at Georgetown University Institute for Reproductive Health are currently investigating a number of simplified NFP methods, including the standard day (fixed day system) and the 2-day algorithm.

Delivery of NFP services could be placed in health care and community settings that do not rely on brief encounters. For example, NFP could be provided in a parish setting by a parish nurse. Catholic and evangelical parishes, orthodox Jewish synagogues, and The Church of Jesus Christ of Latter-day Saints are receptive communities in which parish or congregation nurses could provide NFP services to couples of reproductive age, to those involved in marriage preparation, and chastity education to adolescents. Parish nurses could also train couples to provide basic NFP education to other couples. This would give the nurses more time to focus on couples with difficult menstrual cycle patterns and those with serious reasons to avoid pregnancy.

11 Fehring 
A final way of simplifying and modernizing NFP services would be to integrate the latest fertility monitoring technology into NFP systems. Nurse researchers at Marquette University are incorporating the use of the Clear-plan Easy Fertility Monitor as an aid to learning NFP and fertility awareness. The monitor is accurate, acceptable, simple to use, and its use can be beneficial to a couple's relationship (Severy, 2001). The professional user of the monitor can also purchase a data transfer system that downloads information from the individual monitors with a data transfer card. Professional providers of NFP services at Marquette University are finding that the monitor can be of great help for couples with difficult cycles who have serious reasons for avoiding pregnancy. (See Table 3 for an example using the ClearPlan Easy Fertility Monitor and Figure 2 for cycle information for the case study.)

\section{Conclusion}

NFP is a method of family planning that works with nature by understanding it. It helps couples to integrate and live with their fertility. The dynamics of using NFP may help to strengthen marital life. NFP requires that women and couples be educated about their fertility and learn to monitor fertility as a health record.

From the time of Florence Nightingale, nursing has been known as a profession that helps individuals to work with nature rather than against it. Nursing involves helping to maintain and restore the integrity of the whole person: body, mind, and spirit. Nursing is a profession that promotes health and educates individuals as to how to maintain and achieve higher levels of well-being. The nursing profession would and should be an ideal place for teacher training programs in NFP and for NFP service.

\section{References}

Arevalo, M. (1997). Expanding the availability and improving delivery of natural family planning services and fertility awareness education: Providers' perspectives. Advances in Contraception, 13(2/3), 275-281.

Arevalo, M., Jennings, V., \& Sinai, I. (2002). Eficacy of a new method of family planning: The Standard Days Method. Contraception, 65, 333-338.

Barron, M. L., \& Daly, K. D. (2001). Expert in fertility appreciation: The Creighton Model practitioner. Journal of Obstetric, Gynecologic, and Neonatal Nursing, 30, 386-391.

Behre, H. M., Kuhlage, J., \& Gassner, C. (2000). Prediction of ovulation by urinary hormone measurements with the home use Clearplan Fertility Monitor: Comparison with transvaginal ultrasound. Human Reproduction, 12, 24782482.

12 Fehring 
Bonnar, J., Flynn, A., Fruendl, G., Kirkman, R., Royston, R., \& Snowden, R. (1999). Personal hormone monitoring for contraception. British Journal of Family Planning, 24, 128-134.

Burkhart, M. C., de Mazariegos, L., Salazar, S., \& Lamprecht, V. M. (2000). Effectiveness of a standard-rule method of calendar rhythm among Mayan couples in Guatemala. International Family Planning Perspectives, 26, 131-136.

Cuellar, N. (2002). Tips to increase success for teaching online. CINPlus, 5(1), 1, 4-7. den Tonkelaar, I., \& Oddens, B. J. (2001). Factors influencing women's satisfaction with birth control methods. European Journal of Contraception and Reproductive Health Care, 6, 153-158.

Diocesan Development Program for Natural Family Planning. (2000). National Conference of Catholic Bishops; Standards for diocesan natural family planning ministry (Publication \#5-438). Washington, DC: U.S. Conference of Catholic Bishops.

Doring, G., Baur, S., \& Frank-Herrmann, P. (1990). Report on the results of a representative opinion poll among physicians on the degree of knowledge about and attitudes towards natural family planning in the Federal Republic of Germany in 1988. Geburtshilfe und Frauenheilkunde, 50, 43-48.

Dunlop, A. L., Allen, A. D., \& Frank, E. (2001). Involving the male partner for interpreting the basal body temperature graph. Obstetrics and Gynecology, 98, 133-138.

Dunson, D., Baird, D., Wilcox, A., \& Weinberg, C. (1999). Day-specific probabilities of clinical pregnancy based on two studies with imperfect measures of ovulation. Human Reproduction, 14(7), 1835-1839.

Fehring R. (1995). Physician and nurses knowledge and use of natural family planning. Linacre Quarterly, 62, 22-28.

Fehring, R., Hanson, L, \& Stanford, J. (2001). Nurse-midwives' knowledge and promotion of lactational amenorrhea and other natural family planning methods for child spacing. Journal of Midwifery \& Women's Health, 46(2), 68-73.

Fehring, R., \& Schlidt, A. M. (2001). Trends in contraceptive use among Catholics in the United States: 1988-1995. Linacre Quarterly, 69(2), 170-185.

Frank, E., \& White, R. (1996). An updated basal body temperature method. Contraception, 54, 319-321.

Freundl, G. (1999). European multicenter study of natural family planning (1989-1995): Efficacy and drop-out. Advances in Contraception, 15, 69-83.

Girotto, S., Del Zotti, F., Baruchello, M., Gottardi, G., Valente, M., Battaggia, A., et al.(1997).

13 Fehring 
The behavior of Italian family planning physicians regarding the health problems of women and, in particular, family planning (both contraceptive and NFP). Advances in Contraception, 13, 283-293.

Gray, R., \& Kambic, R. (1984). NFP program evaluation and accountability. In D. Lanctot, M. Martin, \& M. Shivanandan (Eds.), Natural family planning, development of national programs. Washington, DC: IFFLP/FIDAF.

Hatcher, R., Trussell, J., Stewart, F., Cates, W., Stewart, G., Guest, F., et al. (1998). Contraceptive technology. New York: Ardent Media.

Hilgers, T. W., \& Stanford, J. B. (1998). Creighton model NaProEducation Technology for avoiding pregnancy: Use effectiveness. Journal of Reproductive Medicine, 43, 495-502.

Hons, C. (2002, January). Big ten school in cyberspace-A brief history of Penn State's World Campus. T.H.E. Journal (Technological Horizons in Education), pp. 27-29, 30-32.

Howard, M., \& Stanford, J. B. (1999). Pregnancy probabilities during use of the Creighton Model fertility care system. Archives of Family Medicine, 8, 391-402.

Jennings, V., \& Sinai, I. (2001). Further analysis of the theoretical effectiveness of the TwoDay method of family planning. Contraception, 64, 149-153.

Kambic, R. (2000). The effectiveness of natural family planning. Current Medical Research, 11, $11-16$

Lamprecht, V., \& Trussell, J. (1997). Natural family planning effectiveness: Evaluating published reports. Advances in Contraception, 13, 155-165.

Marshall, J. (1968). A field trial of the basal-body temperature method of regulating births. Lancet, 2, 8-10.

Oddens, B. J. (1999). Women's satisfaction with birth control: A population survey of physical and psychological effects of oral contraceptives, intrauterine devices, condoms, natural family planning, and sterilization among 1466 women. Contraception, 59, 277-286.

Piccinino, L. J., \& Mosher, W. E. (1998). Trends in contraceptive use in the United States. Family Planning Perspectives, 30, 4-10.

Severy, L. J. (2001). Acceptability of home monitoring as an aid to conception. The Journal of International Medical Research, 29, 28A-34A.

Sinai, I., Jennings, V., \& Arevalo, M. (1999). The Two Day Algorithm: A new algorithm to identify the fertile time of the menstrual cycle. Contraception, 60, 65-70.

Snowden, R., Kennedy, K. I., \& Leon, F. (1988). Physicians' views of periodic abstinence methods: A study in four countries. Studies in Family Planning, 19, 215-221.

\section{Fehring}


Stanford, J. B., Lemaire, J. C., \& Fox, A. (1994). Interest in natural family planning among female family practice patients. Family Practice Research Journal, 14, 237-249.

Stanford, J. B., Lemaire, J. C., \& Thurman, P. B. (1998). Women's interest in natural family planning. Journal of Family Practice, 46, 65-71.

Stanford, J. B., Thurman, P. B., \& Lemaire, J. S. (1999). Physicians' knowledge and practice regarding natural family planning. Obstetrics and Gynecology, 94, 672-678.

Tommaselli, G. A., Guida, M., \& Palomba, S. (2000). The importance of user-compliance on the effectiveness of natural family planning programs. Gynecological Endocrinology, 14, 8189.

Trussell, J. (1998). Contraceptive efficacy. In R. Hatcher, J. Trussell, F. Stewart, W. Cates, G. Stewart, F. Guest, et al. (1998). Contraceptive technology. New York: Ardent Media.

Wilcox, A. J., Weinberg, C. R., \& Baird, D. (1995). Timing of sexual intercourse in relation to ovulation. Effects on the probability of conception, survival of the pregnancy and sex of the baby. New England Journal of Medicine, 333, 1517-1521.

World Health Organization. (1981). A prospective multicentre trial of the ovulation method of natural family planning: II. The effectiveness phase. Fertility \& Sterility, 36(5), 591-598.

\section{Appendix \\ Figure 1}

Core competencies of professional NFP practice

Professional NFP Practice

\section{NFP Decision Making}

- NFP method that fits the client/couple

- Teaching materials

- Teaching methods

- Data management

- Quality assessment

- Program management

- Ethical concerns

Documentation

- Assessment

- Follow up

- Pregnancy evaluation

- Discontinuation

Integrating NFP into women's health care 
Table 1

Natural Family Planning Teacher Training Programs

Billings Ovulation Method Association-USA (BOMA)

NFP Teacher Training Program

http://www.boma-usa.org/

Couple to Couple League International (CCL)

Natural Family Planning Teacher Training

http://www.ccli.org/teach/index.shtmlh

Family of the Americas Foundation (FAF)

Natural Family Planning Master Teacher Training Program

http://www.familyplanning.net/index-aboutus.html

Marquette University College of Nursing

NFP Teacher Training Program

http://www.mu.edu/nursing/nfp/training.html

Northwest Family Services

Certification Program in NFP

http://www.nwfs.org/index.t?goto=nfp

The Pope Paul VI Reproductive Institute

Fertility Care Allied Health Education Programs

http://www.mitec.net/ popepaul/Education1.htm

U.S. Conference of Catholic Bishops

Department of Natural Family Planning

NFP Teacher Training Program Annotated Directory

http://www.usccb.org/prolife/issues/nfp/trainer.htm 


\section{Table 2}

Marquette University Online NFP Teacher Training Program Modules

\begin{tabular}{|l|l|}
\hline Theory Module & Clinical Session Module \\
\hline Module 1: Introduction and History & Teaching the Marquette Model \\
\hline Module 2: Anatomy and Physiology & NFP Documentation and Follow-up \\
\hline Module 3: Charting Signs of Fertility & NFP Evaluation and Quality Control \\
\hline Module 4: Special Circumstances & Case Management \\
\hline Module 5: Women's Health & Breastfeeding/Post Hormonal Cycles \\
\hline Module 6: Church Teaching & Perimenopause \& Stress \\
\hline Module 7: Marriage \& Family & Infertility and NFP \\
\hline Module 8: Professional Teaching & Women's Health Problems and NFP \\
\hline Module 9: Program Management & Behavioral \& Spiritual Problems \\
\hline
\end{tabular}

17 Fehring 


\section{Table 3}

NFP Case Study: Breast Cancer and Tamoxifen

\section{Background data:}

The wife is 35 years old and the husband 38 . They have been married for 10 years. Both are Roman Catholic. She has used oral hormonal contraception on and off since she was 18 . He is an insurance agent; she is a homemaker.

\section{Reproductive Health Data:}

She has had three pregnancies, which have resulted in three living children, a girl 9 years old, and two boys, one 5 and the other 3 . She was diagnosed with breast cancer in 1999, was treated with breast removal surgery and started on tamoxifen. She will be on the medication for the next 5 years and has been told that under no circumstances is she to become pregnant. The couple refused to be sterilized for religious and ethical reasons. They were referred to the Marquette University College of Nursing Institute for NPF to learn the Marquette Model of NFP that incorporates the use of the Clearplan Easy Fertility Monitor as an aid to learning NFP.

\section{Problem:}

Tamoxifen has an anti-estrogenic effect and will complicate the mucus sign, that is, cervical mucus is a result of a response by endocervical cells to the rising levels of estrogen in the secretory phase of the menstrual cycle.

\section{Solution:}

Use Clearplan ${ }^{\mathrm{TM}}$ monitor as an aid to learning NFP and to help establish the fertile phase of her menstrual cycles. Establish basic infertile pattern of nonchanging mucus. Use yellow color for unchanging patter post-Clearplan peak and ignore the mucus variability.

\section{6-month Follow-up Outcome:}

Prolonged confusing mucus pattern continues-but the peak in cervical mucus correlates with the high readings of the Clearplan monitor. Couple expressed satisfaction and confidence in their family planning method and the ability to identify a fertile window.

The downloaded data from the monitor is illustrated in Figure 2. It shows the variability of the fertile window and the number of test strips used to monitor this variability. As can be seen in Figure 2, the seven menstrual cycles ranged in length from 27 to 42 days. The monitor was able to pick up these changing lengths and the variability of the fertile window. The couple has used the Clearplan Easy Fertility Monitor successfully for more than 3 years as an aid to NFP and to avoid pregnancy. 
Figure 2

Seven cycles of fertility monitoring data.

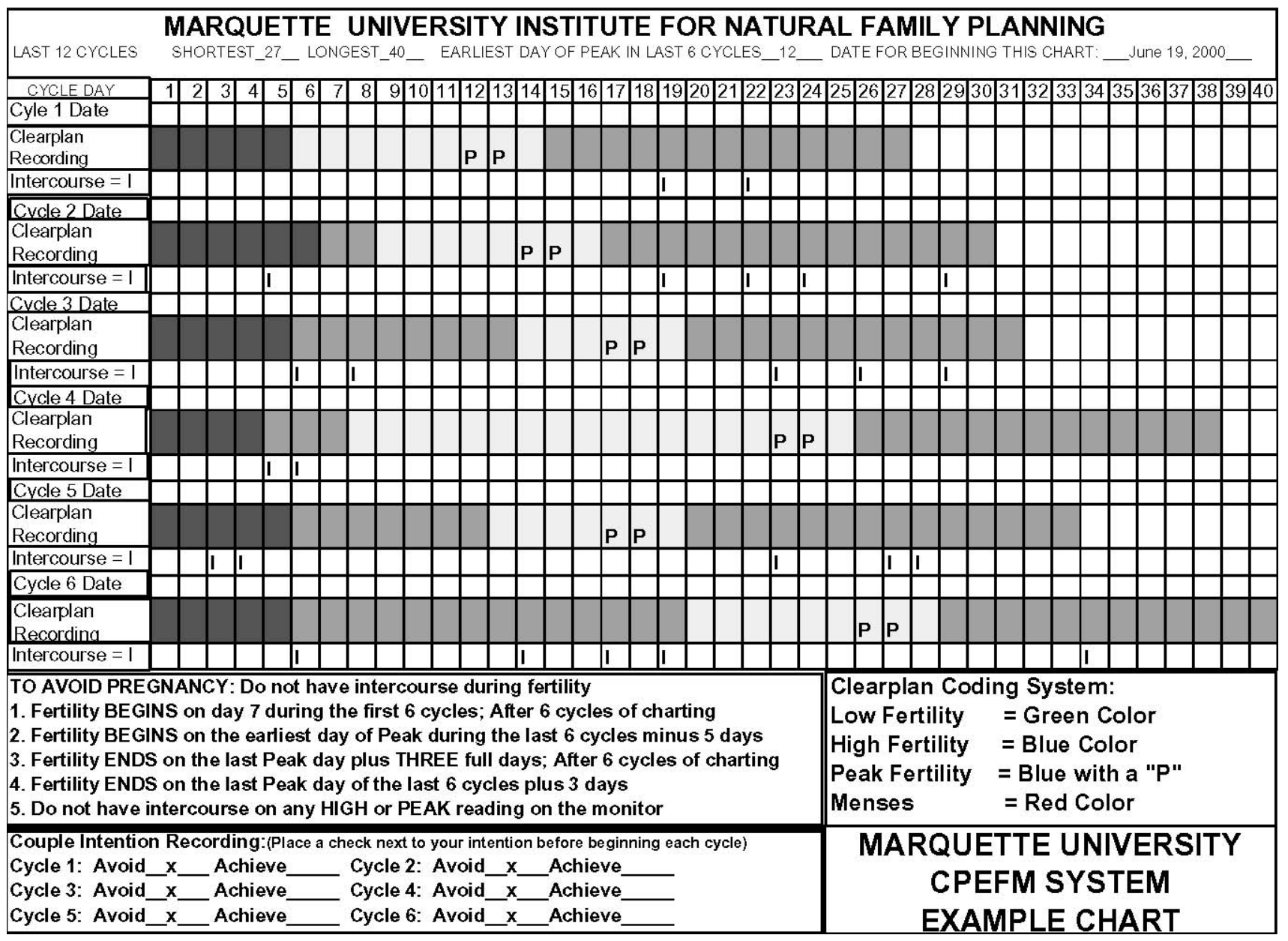

Note: Copyright by Marquette University. Reprinted with permission. 